\title{
INDIVIDUAL AND SECTIONAL COMMUNICATION SYSTEMS IN MANAGEMENT AND DEVELOPMENT OF HUMAN POTENTIAL
}

The article deals with identification of communication systems existing inside the organization: individual, group and organizational. The article deals with possibility to perceive human potential management and development processes as communicational processes, it means, the processes, which we can understand through prism of communication. The quality of basic communicational skills using (active listening, assertivity, empathy and persuasion) is an important condition of permanent growth of human potential management and development system.

Keywords: communication systems, communication, human potential, efficiency, feedback

\section{Introduction}

Each single company and all its integral parts (individuals, groups, teams, departments, sectors) have their own communication system. This system provides immediate or mediate information and communication exchange among the participants of work and extra-work relations in a company. Whereupon it is possible to regard the company, sectional and individual communication systems, which all together form the communication platform of the internal as well as relevant external business environment.

\section{Specification of Communication Systems}

Communication system of a company presents a complex system inside a company, used communication channels, forms, sources, "dictionaries", communication situations and resources, reciprocal sharing, understanding and feedback and implanted visions and expectations of all communicating participants, now members of a company. It can be pointed out that it is the widest form of the sectional communication system, while the setting of the communication in this case, is the whole company. It involves and reflects all the individual and sectional communication systems that exist in the business environment. Despite the fact that company communication system retroacts with the sectional and individual communication systems, which are its immanent parts, it also aims at correct alignment of progress and requisite influence and adaptation to the context of a real and current company situation.

Sectional communication systems in a narrow sense present communication systems of offices, departments, sectors, sections etc. In a larger view, the communication system of the whole hierarchic level of the company management can be taken into the consideration, e.g. communicational system of the lowest, middle or the highest level of management. All the sectional communication systems imply and reflect the individual communication systems. However, compared to simple "sum" of individual communication systems, this system is complicated as well as enriched by necessary integration of group values, norms, habits, visions, preferred communication channels and dictionaries and also by obstacles and barriers occurring in effective communication in a particular environment. From this point of view, sectional communication systems are able to influence in negative and positive sense, both individual communication systems as well as the company one.

Individual communication systems present subjectively built and alleged patterns and forms of communication of an individual (manager or employee) with other individuals or groups inside or outside of the company. Each of these individual systems is in a great part formed by a personality of a particular communicant. It is formed by lifelong working and extra-working experiences, feedback from the others, subjective appraisal of reaction accuracy of a particular individual in communication situations (pleasant, usual or confrontational). It is marked by achieved qualification, pursuit of permanent improvements, aspirations and ambitions of an individual, as well as by influence of the other individual and sectional communication systems.

Moreover, it is usually heavily marked and it is characterised by the occurrence of many communicative errors. Out of these inadequacies the most common are inappropriate formulation of particular information, selective perception, drawing of early and incorrect conclusions, filtration of information, incapability to choose a reliable source of information, inability to ask for, accept and provide a feedback, information overload etc. As these communication faults occur quite often and can have large-scale consequences in a field of possible destruction of individual, sectional and business communication systems, it is necessary to pay an appropriate attention and seriousness to their identification and elimination.

\footnotetext{
* Ing. Martina Blašková, PhD.

University of Žilina, Faculty of Management Science and Informatics, Tel. +421-41-5134455, E-mail: blaskova@fria.fri.utc.sk
} 


\section{Management and Development of Human Potential by Prism of Communication}

Management and development of a human potential is represented by systematically and meaningfully realised processes of judgment and strategically directed level raising of motivation, skills and knowledge of all employees and management personnel in a company. All the processes connected with the human potential can be viewed through the prism of continuous and open communication led in internal and external business environment. It means that the processes of work with people (including processes of strategic preparation of suitable conditions) can be considered as communication processes (scheme 1).

For example, the vision and mission of a company motivate and communicate the future conceptions and present the purpose of a company existence. To have a clear vision and strategy is insufficient. It is necessary to overcommunicate it and clearly understand it in an entire company [3]. Culture and philosophy represents the verbalisation and reflection of values, norms, persuasion, priorities and principles of company manners in a relation to employees, customers, own development, public and nature. Strategic objectives of development of the human potential constitute desired conditions and wanted results in this field. Personal strategy and politics imply trajectories, constraints, sources, principles, practices and effective realisation of particular personal processes.
Work analysis is communication about difficulty, responsibility, merits and character of a particular working place - e.g. by the use of questionnaires, interviews, observations (acquisition of verbal manners and monitoring of non-verbal manners of employees as well as management personnel in their job performance). Acquisition, i.e. process of gaining and selection, means representation of requirements and attraction of both communication sides company representatives as well as applicants. Orientation is a communication-adaptation-socialisation process, which in full lean on preliminary, running and consecutive informative interviews. Allocation implies, on the basis of communication of visions and real output as well as company potentials, movement of employees in a company. Yet, always with an essential and early notice of future impacts on employees and managers.

In an evaluation process of a complex working output, employees expect an opportunity to confront their own visions about themselves and their potentials with the visions of their superior and according to that they orientate their own working and qualifying endeavour. They also expect to gain the feedback, i.e. information about their job performance. All the same they need to have a space to submit their own conception of remuneration [1]. Concurrently, managers in a position of evaluators need a feedback about the efficiency of their motivation-communicational endeavour exerted on their subordinate colleagues.

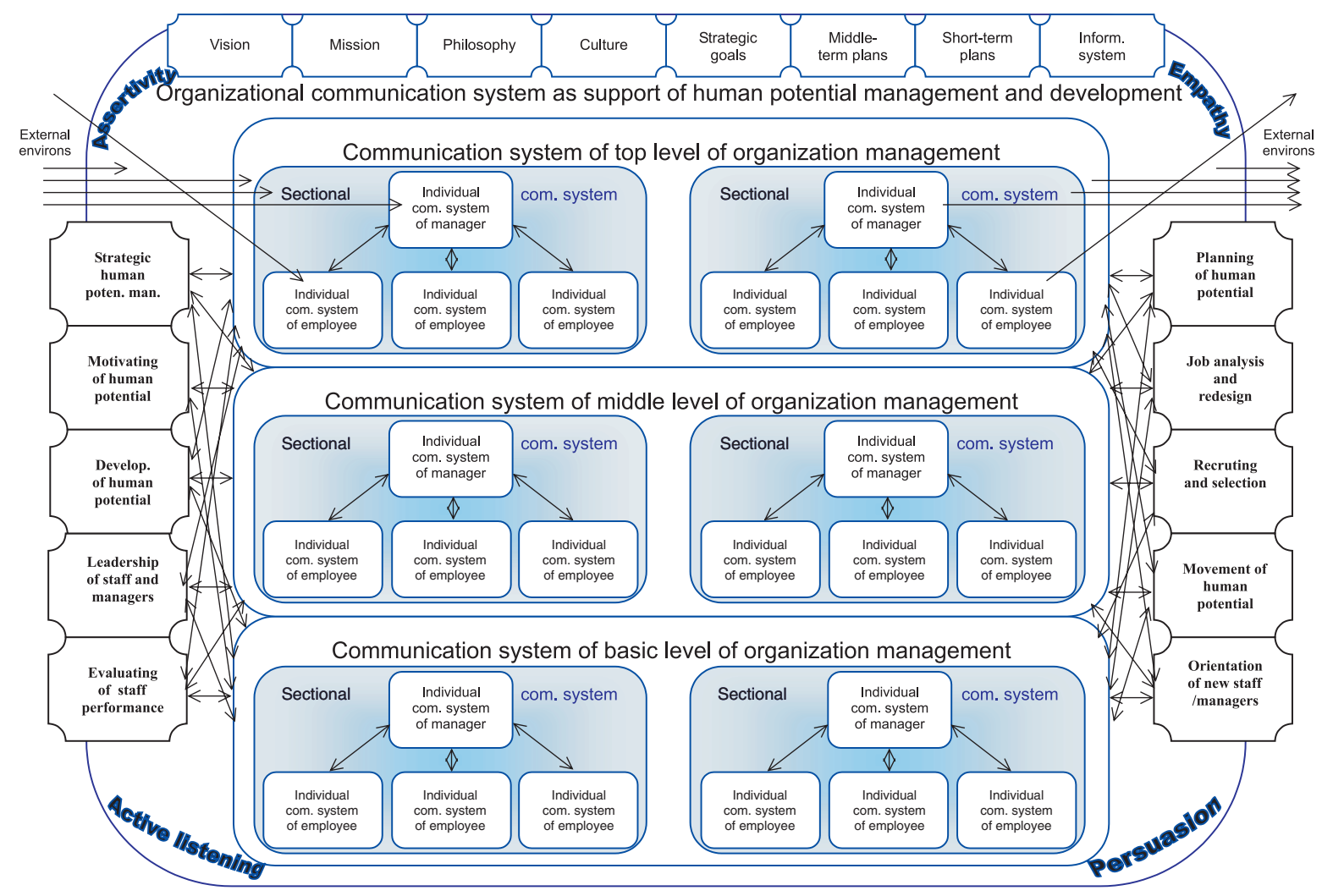

Scheme 1 Communication systems and human potential management and development system 


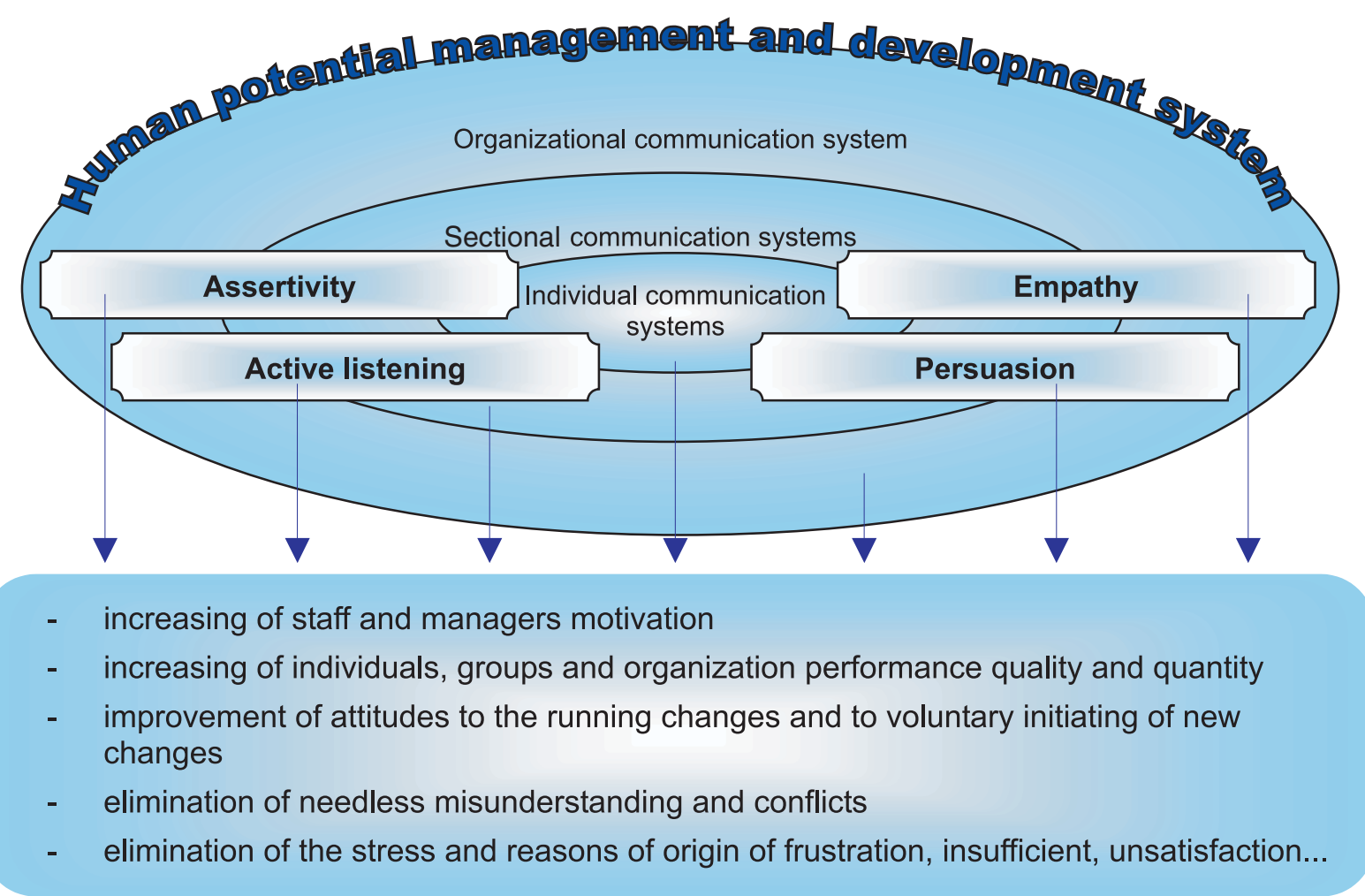

Scheme 2 Positive consequences of communicational skills implying in organization

Leadership is based on communication and direction of employees and managers to adjust their individual aims and individual communication systems with the sectional and company ones. Education and development of knowledge and skills represent communication of all the other possibilities of the professional and personal development, while quite often it concentrates on the communication skills training and elimination of basic communication mistakes and barriers.

Motivation presents recognition and accosting of value scales, needs and aims of employees by open verbal and also non-verbal communication (application of persuasion, active listening and emphaty). Relevance of effective communication in motivation stress out the fact, that "the highest value is achieved when employees identify themselves with their working tasks and are convinced about their importance." [2].

\section{Development of Communication Skills}

Common way of enhancement and harmonisation of individual and sectional communication systems with the company one, and also dynamisation of all processes of management and development of human potential, is the way of development and application of basic communicative skills of all employees and managers. These skills, in contemporary understanding, are assertivity (skill to actively and "ethically" communicate), emphaty (skill to understand the view and experiences of a communication partner), active listening (skill to show the interest in communication topic and com- munication partner) and persuasion (skill to positively persuade). Suitable integration or creation of these communication skills into communication systems of individuals and sections will be definitely reflected in enhancement of complex results of employees, managemers as well as a company in future (scheme 2).

Call for meaningful and balanced application of these communication skills can be directed from the complex company communication system. However, individuals or groups in a company can also invoke it so it can be directed even from the individual and sectional communication systems. This call can be also invoked by individual processes of management and development of human potential in a company as a natural reaction to a need to eliminate the faults and demonstrative inefficiency.

\section{Conclusion}

Enhancement of individual, sectional and company communication system can positively influence and generate certain pressure on dynamisation of particular processes of management and development of human potential and vice-versa. This positive reciprocal influence of quality of communication systems and working processes with the human potential is realised mostly by application and acceptation of direct and indirect feedback and by use of ideas and suggestions made by employees and management in a company. It is also realised by common sharing of communicated expectations and duties and by endeavour to gain, maintain and communicate "the wisdom" of all members of the company on the basis 
of learning from the previous positive and negative experiences, reciprocal knowledge and skill beneficiation and effective use and development of unique human potential.

Enhancement of communication systems can be achieved by, e.g. meaningfully directed arrangements, which are identified as knowledge of outputs of evaluation processes of complex employees and management job performance. It could be achieved by higher motivation effort of managers, staff managers and ordinal employees and by application of creative (participative) management centred on this field. Desired planing of human potential and its development in short-term, medium-term and long-term time and logical perspective can form it. In this layer an analysis of working places and especially the way and philosophy of cre- ation of new and redesign of already existing places can be very helpful. Equally, the process of new employees orientation and their consecutive placement can obtain the view of balanced and desired reinforcement of communication skills and communication systems of individuals, sections and company.

Enhancement and dynamisation of system of management and development of human potential can be achieved by creation of reciprocal, open and unblocked communication environment, and by high quality and balanced function of individual as well as sectional communication systems of a company.

\section{Acknowledgement}

This paper is supported by the grant of VEGA 1/1243/04.

\section{References}

[1] HITKA M.: Hodnotenie práce riadiacich pracovníkov vo výrobnom podniku. Zvolen. Vydavatelstvo TU Zvolen. 2002

[2] KACHAÑÁKOVÁ A.: Podniková kultúra. Bratislava. Ekonóm. 2003

[3] KUCHARČÍKOVÁ A. - VODÁK J.: Dnešný pohlad na zajtrajšiu budúcnost' - tvorba a implementácia stratégie. In: Produktivita 5/2002. 